\title{
Experimental Investigation on Outdoor and Indoor PM2.5 and PM10 in Supermarkets in Bandung During Covid-19 Pandemic
}

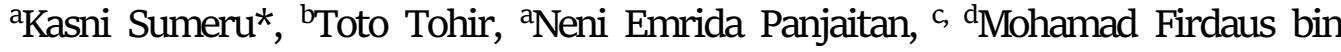 \\ Sukri \\ aDepartment of Refrigeration \& Air Conditioning Engineering, Politeknik Negeri Bandung, West Java \\ 40559, Indonesia \\ bepartment of Electrical Engineering, Politeknik Negeri Bandung, West Java 40559, Indonesia \\ 'Green and Efficient Energy Technology (GrEET) Research Group, Universiti Teknikal Malaysia \\ Melaka, Hang Tuah Jaya, 76100 Durian Tunggal, Melaka, Malaysia \\ ${ }^{\mathrm{d}}$ Faculty of Mechanical Engineering, Universiti Teknikal Malaysia, Hang Tuah Jaya, 76100 Durian \\ Tunggal, Melaka, Malaysia
}

Received 30 July 2021; accepted 17 September 2021

\begin{abstract}
During the Covid-19 pandemic, the number of visitors at the trade center in Bandung was much reduced as compared to before pandemic, which was only about 30\% of normal conditions. The present study is to investigate particulate concentrations of PM2.5 and PM10 in three supermarkets in Bandung, namely Kosambi, Batununggal Modern and Cinunuk supermarkets during the pandemic of Covid-19. Air sampling was measured using a particulate counter CEM DT96 for 11 hours, from 06:00 AM to 5:00 PM, local time. The results showed that the average of outdoor and indoor concentrations of PM10 in two supermarkets (Batununggal Modern and Griya Cinunuk) was lower than standard during that 11 hour. As for the outdoor concentrations of PM2.5, both markets exceeded the standard for several hours in the morning. In general, it can be concluded that the outdoor and indoor concentrations of PM2.5 and PM.10 during pandemic were below the standard, except in the morning before 10:00 AM.
\end{abstract}

\section{KEYWORDS \\ Air pollution \\ PM2.5 and PM10 \\ Indoor and outdoor \\ Supermarket \\ Bandung}

\section{INTRODUCTION}

The Covid-19 pandemic was declared by The World Health Organization (WHO) on January 30, 2020 (Chen et al., 2020; El Zowalaty \& Järhult, 2020; Li et al., 2020). Meanwhile, in Indonesia, restrictions on community activities began on April 15, 2020. This restriction led to a decrease in visit by publics to the supermarkets, as well as reducing the number of vehicles passing through those supermarkets. From an economic point of view, it creates a negative impact, however, in terms of environmental impact, it will significantly reduce the level of air pollution. 
Particulate matter (PM) is a mixture of solid and micro droplet of liquid in the air. Those with a diameter bigger and less 10 microns can be inhaled into the human respiratory system. The smaller the diameter of the particulate, the higher its deposition in the lungs. As a result, PM2.5 has higher percentage of deposition in the lungs, as compared to PM1O. In other words, PM.25 is more dangerous than that of PM10 ("IARC Monographs on the Evaluation of Carcinogenic Risks to Humans," 2010; Nevers, 1999). The short and long term effects of PM10 on human health have been reported by Gauvin et al. (Gauvin et al., 1999) and Ostro et al. (Ostro et al., 1998).

In the urban area, PM is mostly emitted from anthropogenic sources, such as industrial processes and vehicle exhaust (Ostro et al., 1998). Consequently, Covid-19 pandemic has created lockdown situation in affected countries and therefore lead to reduce number in human activities and vehicle operating in urban areas. As a result, the concentration of PM will also decrease during this pandemic.

Bandung is one of the largest cities in Indonesia with population of around 3 million peoples. An experimental study conducted before Covid-19 pandemic in 2017 reported that PM10 concentration in urban areas of Bandung reached 160 to $190 \mu \mathrm{g} / \mathrm{m3}$, and it is higher than that of the standard level (Pratama \& Sofyan, 2020). The PM10 standard level in Indonesia for outdoor air is set at $150 \mu \mathrm{g} / \mathrm{m} 3$. Meanwhile, based on open literature, no papers have been found reporting the indoor concentration of PM10 in Bandung before Covid-19 pandemic. In order to know the effect of limited community activities during Covid-19 pandemic on outdoor and indoor air pollution in Bandung, this study was carried out in three supermarkets located in the urban areas of Bandung.

\section{METHOD}

\section{Location Description}

The study was conducted at three supermarkets in the urban area of Bandung as depicted in Fig. 1. The figure shows that two supermarkets are located in the central Bandung, namely Kosambi and Batununggal Modern, and one supermarket is located in the northeast of Bandung, that is Griya Cinunuk. The selection of these locations was based on the differences in the physical characteristics of these supermarkets. The supermarket located at Kosambi was the first being established, followed by supermarket at Batununggal Modern and Griya Cinunuk. Meanwhile, in terms of the number of visitors, Batununggal Modern is the highest, followed by Kosambi and Griya Cinunuk. 


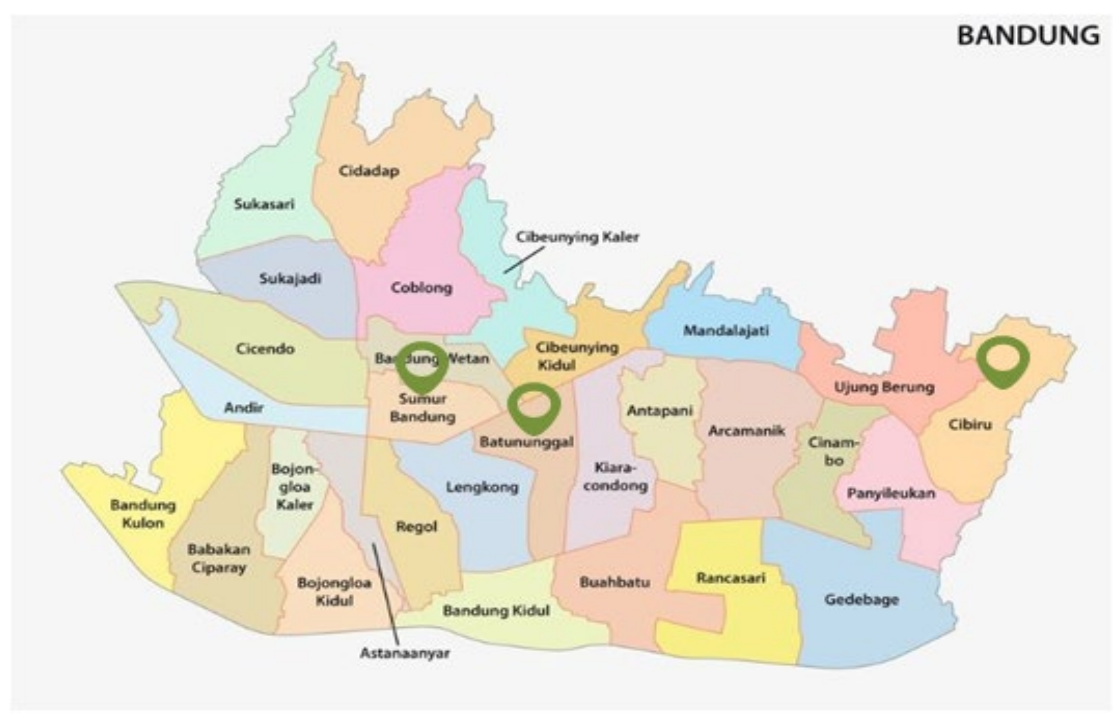

\section{Sampling Method}

This study was carried out from May to June 2021. The measurement was conducted for 21 days, with 7 days for each location. Data collection was taken every hour for 11 hours, from 06:00 AM to 5:00 PM. The concentrations of PM2.5 and PM10 were measured using a directreading instrument particle CEM Instrument DT-96. This instrument has the ability to measure particle sizes of 10 and $2.5 \mu \mathrm{m}$, air relative humidity, and air temperature. The particulate concentrations were measured with sampling time of 15 seconds. Measurements of the outdoor PM2.5 and PM1o concentrations were carried out at two locations, namely near the public roads and closed to the market.

\section{RESULT AND DISCUSSION}

\section{Outdoor PM1o Concentration}

Figure 2 depicts PM10 concentrations of outdoor in three supermarkets, i.e., Kosambi, Batununggal Modern and Griya Cinunuk. The outdoor concentrations in those locations are average of concentration in the public roads and closed to the supermarket entrances. The figure shows that for 11 hours of measurements, the PM1 concentrations in two supermarkets, namely in Batununggal and Griya Cinunuk are lower than that of standard of air pollution in Indonesia. The air pollution standard in Indonesia of $150 \mu \mathrm{g} / \mathrm{m} 3$ is shown in Fig. 2 with a dash line. The PM10 concentration in Kosambi, is above the standard before 10:00 AM, and the highest concentration occurred at 6:00 $\mathrm{AM}(273 \mu \mathrm{g} / \mathrm{m} 3)$. It is because the vehicle traffic in front of the Kosambi supermarket before 10:00 AM is denser than that of two supermarkets at Batununggal Modern and Griya Cinunuk. The figure also shows that the highest concentration of PM1O in Kosambi and Batununggal Modern occurred at 06:00 AM, that is around 273 and $140 \mu \mathrm{g} / \mathrm{m} 3$, respectively. Meanwhile, the highest concentration of PM10 in Griya Cinunuk 
occurred at 06:00 AM (122 $\mu \mathrm{g} / \mathrm{m} 3)$. The average concentrations of PM10 for 11 hours of measurements in Kosambi, Batununggal Modern and Griya Cinunuk are 127, 68 and 64 Hg/m3, respectively.

Results in this study are lower as compared to result found by Pratama and Sofyan (2017) due to measurement was conducted during Covid-19 pandemic in 2021. Pratama and Sofyan (Pratama \& Sofyan, 2020) reported that the PM10 concentration in urban area of Bandung in 2017 reached 160 to $190 \mu \mathrm{g} / \mathrm{m} 3$. As a result, limiting people's activities during the Covid-19 pandemic reduces air pollution significantly.

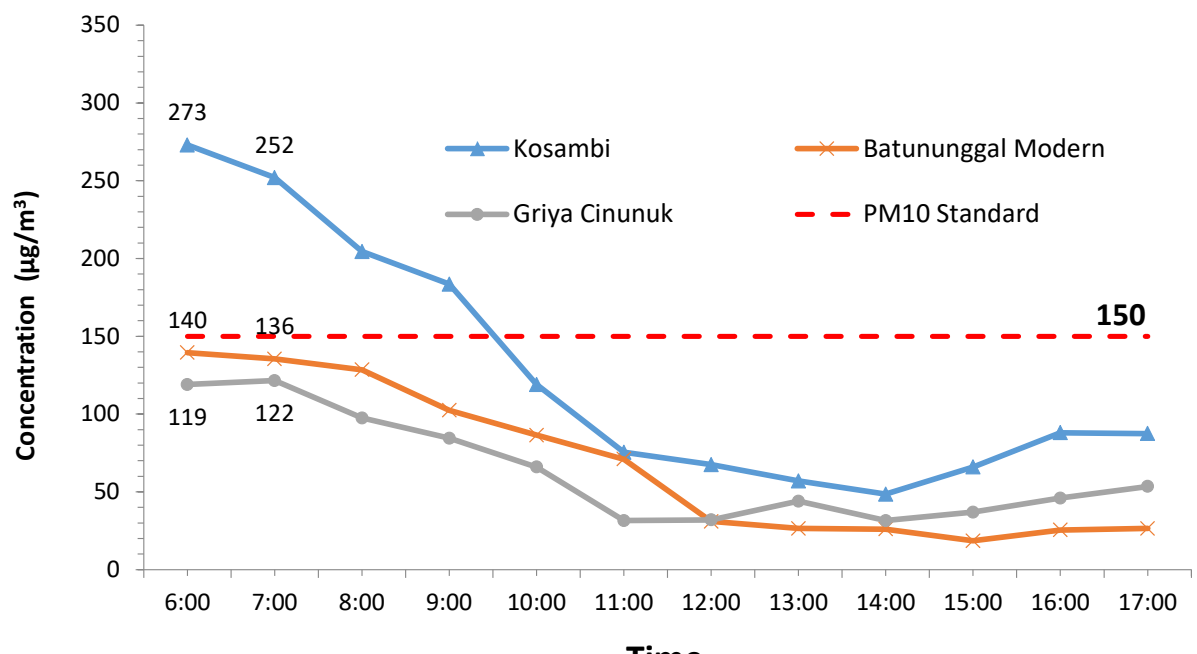

Figure 2. Outdoor PM1o concentrations for three supermarkets

\section{Indoor PM1o Concentration}

Measurement of indoor PM10 concentrations were carried out at three locations for each supermarket. The points in Fig. 3 are the average value of three measured data, illustrating indoor PM10 concentrations in three supermarkets, i.e., Kosambi, Batununggal Modern and Griya Cinunuk. The trend in Fig. 3 is similar to Fig. 2. In other words, the indoor concentration of PM1O is directly affected by outdoor concentration. Similar to Fig. 2, the highest indoor PM1O concentration occurred in Kosambi at 06:00 AM (300 $\mu \mathrm{g} / \mathrm{m} 3)$, and it is double than that of standard (150 $\mu \mathrm{g} / \mathrm{m} 3)$. However, indoor PM10 concentration in Kosambi continued to decrease with time and reached below standard after 09:00 AM. Based on the Indonesia Government Regulation No. 41 of 1999, the standard of PM1O and PM2.5 for 24 hours is 150 and $65 \mu \mathrm{g} / \mathrm{m3}$.

Indoor PM1o concentrations in Batununggal and Griya Cinunuk were under standard for 11-hour measurements. The highest indoor PM10 concentration in Batununggal Modern and Griya Cinunuk occurred at 06:00 AM (147 $\mu \mathrm{g} / \mathrm{m3})$ and 07:00 AM (108 $\mu \mathrm{g} / \mathrm{m3})$, respectively. Meanwhile, the average indoor concentrations in Kosambi, Batununggal Modern and Griya Cinunuk were recorded at 128, 81 and $55 \mu \mathrm{g} / \mathrm{m} 3$, respectively. It can be seen that the average indoor concentration of PM1O in Kosambi and Batununggal is slightly higher than that of outdoor concentration. It indicates that indoor concentration of PM10 is not always lower than 
that of outdoor. A different phenomenon occurred in the Griya Cinunuk, where the average indoor concentrations is lower than that of outdoor concentration.

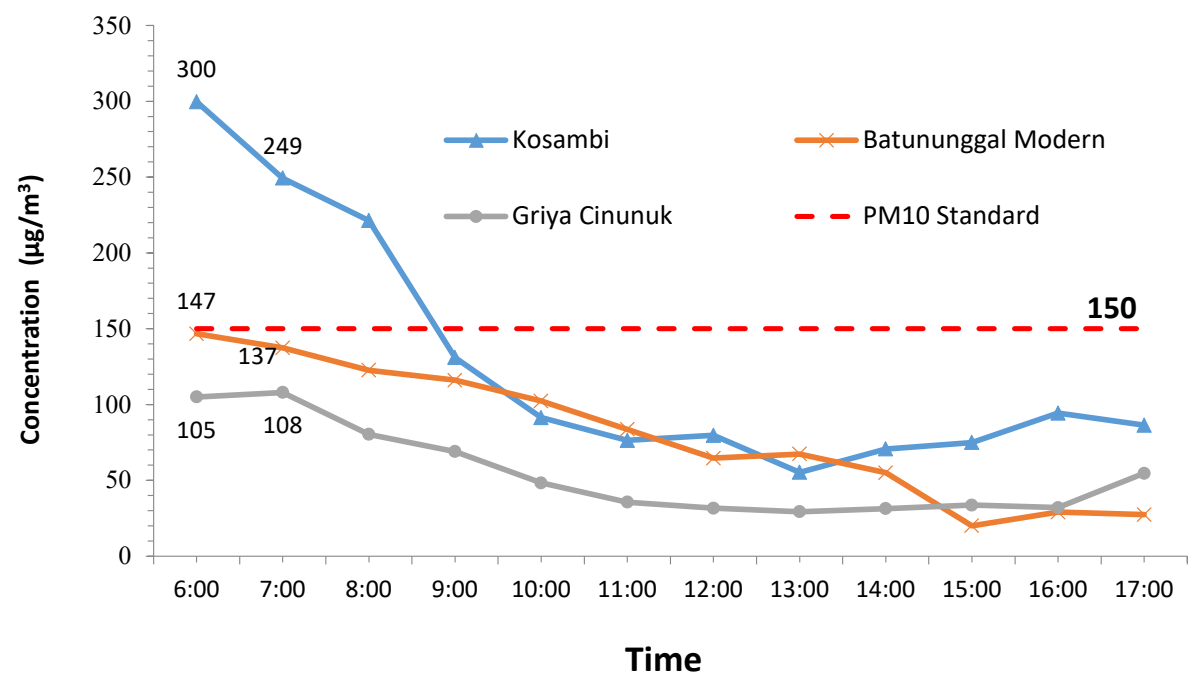

Figure 3. Indoor PM10 concentrations for three supermarkets

The comparison of outdoor and indoor concentrations of PM1O in Kosambi is illustrated in Fig. 4. It can be seen that the trend of the two graphs is similar, namely high in the morning and falling below the standard in the midday to the late afternoon. The figure shows that at 09:00 $\mathrm{AM}$, indoor concentration was already lower than that of standard, but outdoor concentration was still higher than that of standard. The figure shows that indoor concentrations are not always lower than outdoor concentrations. At certain hours the indoor concentration is higher than the outdoor concentration, but at certain hours the indoor concentration is higher than the outdoor concentration. However, it can be concluded that the outdoor concentration affects the indoor concentration, because both graphs have a similar trend.

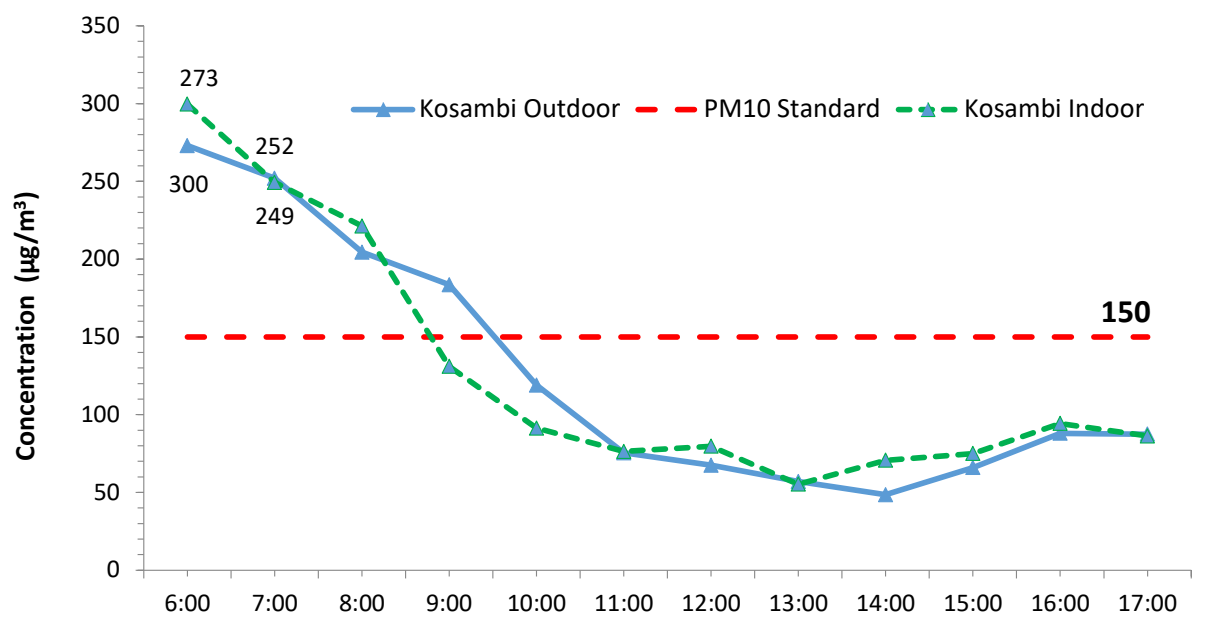

Time

Figure 4. Comparison of indoor and outdoor PM1o concentrations in Kosambi 


\section{Outdoor PM2.5 Concentration}

Figure 5 illustrates PM2.5 concentrations of outdoor in three supermarkets. The trend of this figure is similar to that of PM10 concentrations as shown in Figure 2. The difference is the quantity of concentrations, where the PM2.5 concentrations for 11 hours was lower than that of the PM10. The difference in concentration of PM1O and PM2.5 is particulate with a diameter of less than $10 \mu \mathrm{m}$ and higher than $2.5 \mu \mathrm{m}$. For example, at 06:00 AM in Kosambi, the concentrations of PM10 and PM2.5 were $273 \mu \mathrm{g} / \mathrm{m} 3$ and PM2.5 $138 \mu \mathrm{g} / \mathrm{m} 3$, respectively. There was a difference of $138 \mu \mathrm{g} / \mathrm{m} 3$ between PM1O and PM2.5 concentrations. It indicates that the PM2.5 concentrations at 06:00 AM is about 50.6\% of PM10. This means that $49.4 \%$ of particulate in Kosambi outdoor at 06:00 AM is 2.5 to $10 \mu \mathrm{m}$ in diameter.

For cases in Batununggal Modern and Griya Cinunuk, the PM10 concentrations at 06:00 AM were at 140 and $119 \mu \mathrm{g} / \mathrm{m} 3$, respectively. Meanwhile, PM2.5 concentrations in these two supermarkets were at 82 and $77 \mu \mathrm{g} / \mathrm{m} 3$, respectively. There are differences of $58 \mu \mathrm{g} / \mathrm{m} 3$ (58.6\%) in Batununggal Modern and $42 \mu \mathrm{g} / \mathrm{m} 3$ (64.7\%) in Griya Cinunuk, between PM10 and PM2.5 concentrations. It means that the PM2.5 concentrations in two supermarkets are more than $50 \%$, and the rest are between 2 and $10 \mu \mathrm{m}$ in diameter.

The interesting thing in Figure 5 is that the PM2.5 concentrations in two supermarkets were higher than that of the standard before 09:00 AM, and after 10:00 AM in Batununggal. Unfortunately, PM2.5 concentration data before Covid-19 pandemic in Bandung is not found in the literature for further comparison of before and after the Covid-19 pandemic. However, it can be seen in Figure 5 that the PM2. 5 concentrations in three supermarkets is higher than that of in the morning, so it very likely that the PM2.5 concentration would be above standard before Covid-19 pandemic for 11 hours of measurement.

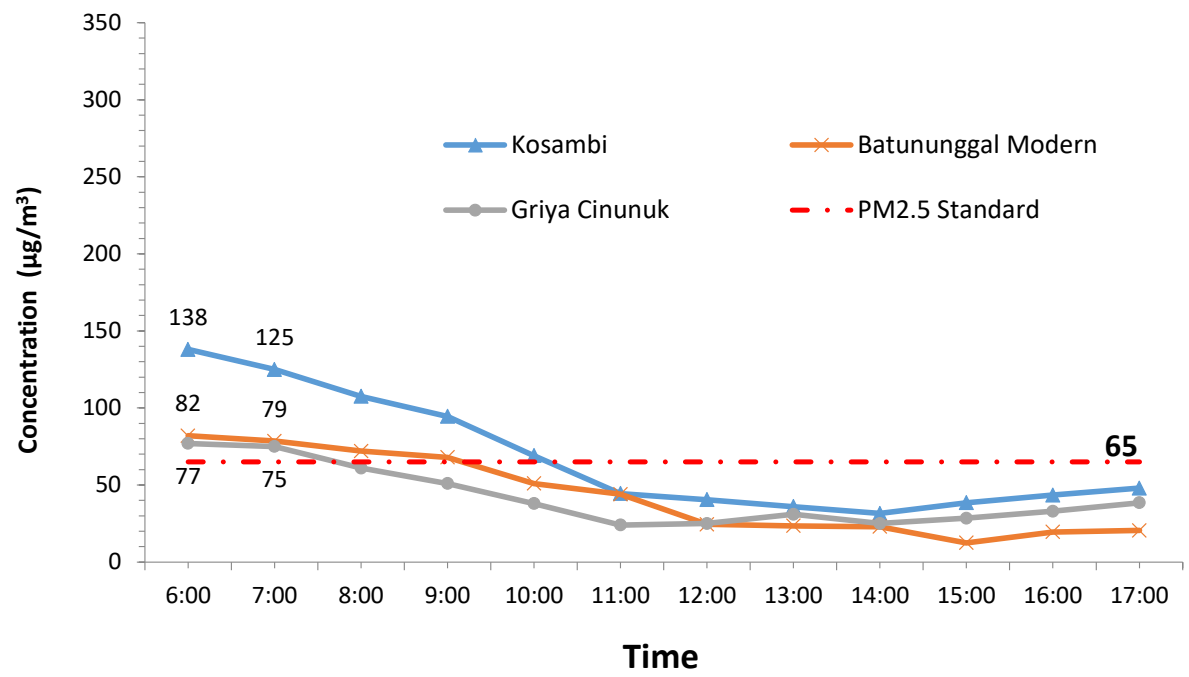

Figure 5. Oudoor PM2.5 concentrations for three supermarkets

Figure 6 depicts the indoor PM2.5 concentrations in three supermarkets. It can be seen that the trend of indoor PM2.5 concentrations is similar to the outdoor PM2.5 concentrations for 
11 hours. The figure shows that the PM2.5 concentrations in Kosambi is the highest, while in the Griya Cinunuk is the lowest. In Kosambi, the PM2.5 concentrations were lower than the standard before 10:00 AM, whereas in Griya Cinunuk only at 07:00 AM was slightly above the standard, while the rest were under the standard. It means that indoor air quality in Griya Cinunuk has good quality during Covid-19 pandemic as compared to two other supermarkets (Kosambi and Batununggal Modern).

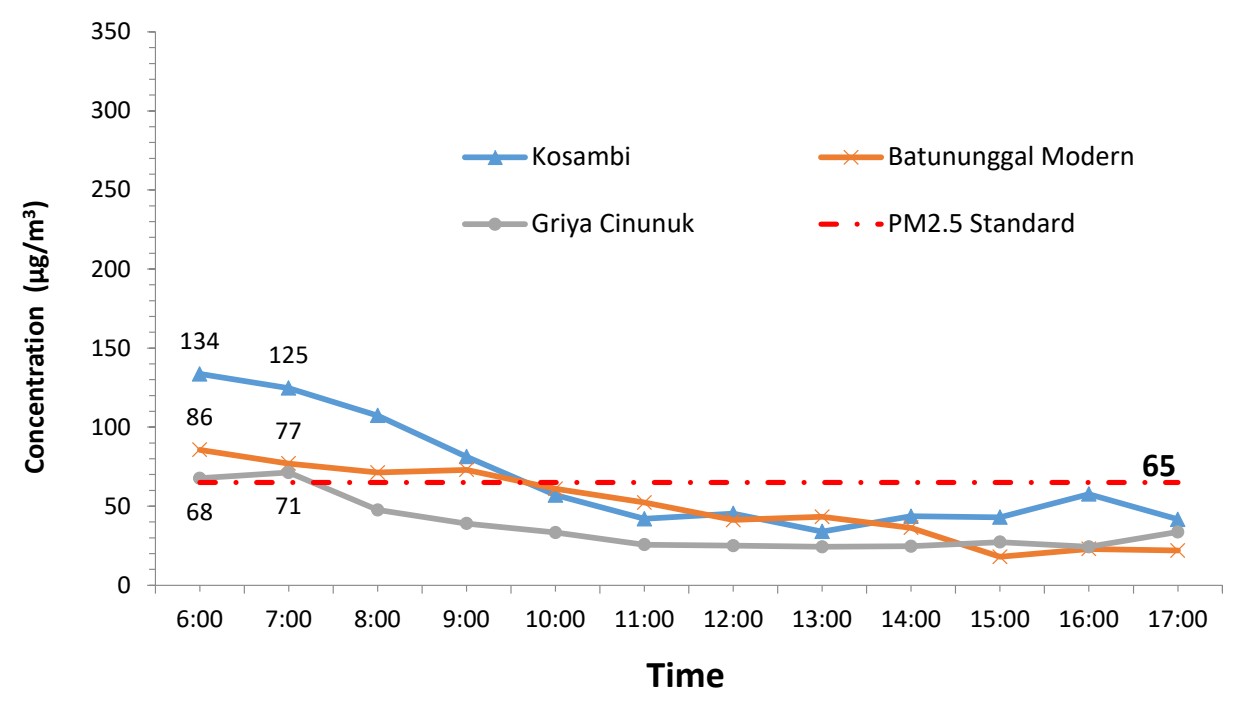

Figure 6. Indoor PIM2.5 concentrations for three supermarkets

Because Kosambi supermarket has the highest concentration of PM2.5 in outdoor and indoor, as shown in Figure 5 and 6, furthermore the outdoor and indoor concentrations will be compared at that location. Figure 7 depicts comparison of the outdoor and indoor PM2.5 concentrations in Kosambi supermarket. The figure shows that two graphs have similar trend. It indicates that the indoor concentration. At 08.00 AM to 11.00 AM, the indoor concentration is lower than outdoor concentration, but from 01.00 PM to 4.00 PM, on the contrary, i.e., indoor is higher than outdoor. Based on the figure, similar to PM10, the indoor PM2.5 concentration in Kosambi supermarket is affected by outdoor concentration. While the outdoor PM2.5 concentration is influenced by the activities of people and vehicles passing through in the area. It indicates that when the Covid-19 pandemic ends and people's activities return to normal, it is most likely the outdoor and indoor PM2.5 concentrations will be above the standard. Although the Covid-19 pandemic has a negative impact on the community's economy, but the Covid-19 pandemic has positive effect on the air quality in urban area of Bandung. Because the PM2.5 concentration in Kosambi supermarket is still above the standard in the morning, as a result, it is recommended to go to the supermarket after 10:00 AM. 


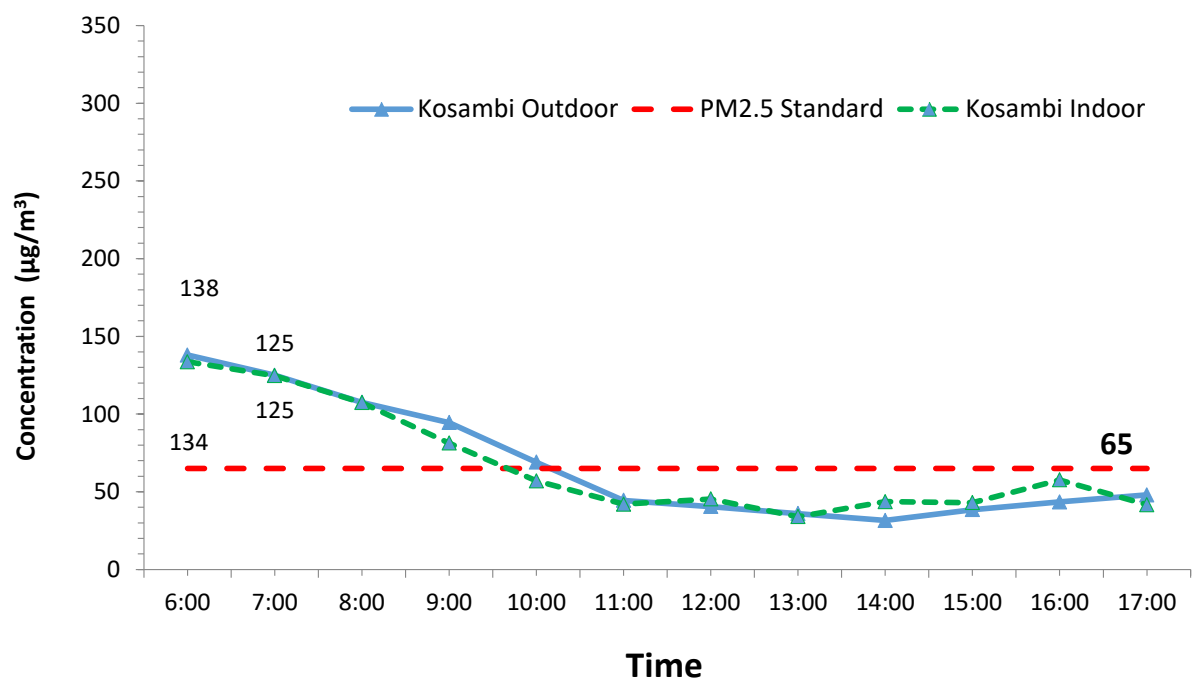

Figure 7. Comparison of indoor and outdoor PM2.5 concentrations in Kosambi

\section{CONCLUSION}

The Covid-19 pandemic requires the government to limit the movement of people's activities. The decline in community activities due to restrictions on community movement has a positive impact on air quality in Bandung. It can be seen that the concentrations of PM10 and PM2.5 in the three supermarkets are only above the standard in the morning, while in the midday until the afternoon, the concentration is below the standard. For this reason, if community want to breathe air with a concentration below the standard during the pandemic, it is advisable to go to the Bandung urban area after 10:00 AM. In order to determine the correlation between community activities and air pollution levels in these three supermarkets, it is necessary to measure the PM1O and PM2.5 concentrations after the pandemic period ended. The data obtained can be used as a reference for decision makers to regulate the quantity of activities in the three supermarkets, in particular, and the urban area of Bandung in general.

\section{ACKNOWLEDGMENTS}

The authors are grateful to Politeknik Negeri Bandung for the facilities and management support. This research was carried out under the Kemendikbudristek Fund, No. 250/E41/AK.04.PT/2O21.

\section{REFERENCES}

Chen, N., Zhou, M., Dong, X., Qu, J., Gong, F., Han, Y., Qiu, Y., Wang, J., Liu, Y., Wei, Y., Xia, J., Yu, T., Zhang, X., \& Zhang, L. (2020). Epidemiological and clinical characteristics of 99 cases of 2019 novel coronavirus pneumonia in Wuhan, China: a descriptive study. The Lancet, 395(10223), 5O7-513. https://doi.org/10.1016/So140-6736(20)30211-7

El Zowalaty, M. E., \& Järhult, J. D. (2020). From SARS to COVID-19: A previously unknown SARSrelated coronavirus (SARS-CoV-2) of pandemic potential infecting humans - Call for a One Health approach. One Health, 9. https://doi.org/10.1016/j.onehlt.2020.100124 
Gauvin, S., Zmirou, D., Pin, I., Quentin, J., Balducci, F., Boudet, C., Poizeau, D., \& Brambilla, C. (1999). Short-term effect of exposure to suspended particulate matter (PM10) on the respiratory function of urban asthmatic and control adults. Journal of Environmental Medicine, 1(2), 71-79. https://doi.org/10.1002/(sici)1099-1301(199904/06)1:2<71::aid-jem13>3.3.c0;2-1

IARC monographs on the evaluation of carcinogenic risks to humans. (2010). In IARC Monographs on the Evaluation of Carcinogenic Risks to Humans (Vol. 93). https://doi.org/10.1136/jcp.48.7.691-a

Li, P., Xie, M., \& Zhang, W. (2020). Clinical characteristics and intrauterine vertical transmission potential of coronavirus disease 2019 infection in 9 pregnant women: a retrospective review of medical records. American Journal of Obstetrics and Gynecology, 223(6), 955-956. https://doi.org/10.1016/j.ajog.2020.08.059

Nevers, N. de. (1999). Air Pollution Control Engineering (2nd ed.). MoGraw-Hill Science.

Ostro, B. D., Lipsett, M. J., \& Dus, R. (1998). Particulate matter and asthma: A quantitative assessment of the current evidence. Applied Occupational and Environmental Hygiene, 13(6), 453-460. https://doi.org/10.1080/1047322X.1998.10389571

Pratama, A., \& Sofyan, A. (2020). PM10 air pollution dispersion analysis in Bandung city using WRFCHEM data assimilation. Journal of Environmental Engineering, 26. 